\title{
INFLUENCE OF PRELIMINARY OSMOTIC DEHYDRATION ON DRYING KINETICS AND FINAL QUALITY OF CARROT (DAUCUS CAROTA L.)
}

\author{
Stefan J. Kowalski, Dominik Mierzwa* \\ Poznań University of Technology, Department of Process Engineering, Institute of Technology and \\ Chemical Engineering, pl. Marii Skłodowskiej-Curie 2, 60-965 Poznań, Poland
}

\begin{abstract}
This paper concerns convective drying of carrot preliminary dehydrated in aqueous solutions of three types of osmotic agents (sucrose, fructose, glucose). Three solution concentrations (20, 40 and $60 \%$ ) were examined to work out efficient conditions of osmotic dewatering. The parameters such as water loss (WL), solid gain (SG) and osmotic drying rate (ODR) indicating the real efficiency of osmotic dehydrations (OD) were determined. The samples dehydrated with osmotic solutions underwent further convective drying to analyze influence of dehydration process on drying kinetics and final products quality. The quality of products was assessed on the basis of visual appearance of the samples and colorimetric measurements. It was found that osmotic pretreatment improves significantly the final product quality as the samples were less deformed and their colour was better preserved compared to samples, which had not been preliminarily dehydrated. Preliminary dehydration, however, did not influence significantly the overall drying time of the samples.
\end{abstract}

Keywords: osmotic dehydration, convective drying, carrots, drying kinetics, product quality

\section{INTRODUCTION}

It is known that fresh fruit and vegetables constitute an important source of valuable and essential nutrient substances such as vitamins, minerals, cellulose and others. Unfortunately, fresh fruit and vegetables cannot be stored for a long time. Stability of raw biological materials such as fruit and vegetables is conditioned by moisture content and water activity. Water activity $\left(a_{w}\right)$ in chemistry and food science is defined as the ratio of water vapor pressure over the material to the water pressure over the pure water surface at the same temperature. High moisture content (for fruit and vegetables often higher than 80\%) and water activity are conducive to developing of germs and putrefactive bacteria, which are responsible for decaying processes. For this reason fruit and vegetables are processed to extend their shelf life.

Drying, especially hot air drying, is one of the most often applied industrial methods of preserving post harvested fruit and vegetables. The main purpose of this operation is a decrease of water content and activity, which results in inhibition of bacteria evolution and biochemical reactions (both enzymatic and non-enzymatic). This process stabilizes and prolongs the shelf life of fruit and vegetables and enables their longer storage and further utilization. Thanks to weight and volume reduction, packaging and transportation costs are reduced, which is another benefit of drying operation (Mujumdar and Law, 2010; Sagar and Suresh Kumar, 2010). 
However, drying processes may cause a deterioration of products' quality. High temperature and longtime drying often change the shape, color, taste, aroma and nutrient properties of fruit and vegetables (Korkida et al., 1998; Markowski et al., 2006; Santos and Silva, 2008; Vázquez-Vila et al., 2009). Besides, drying is also one of the most energy-intensive unit operations in food processing industry. It was stated that drying easily accounts for up to $15 \%$ of all industrial energy usage (Chua et al., 2001; Kudra, 2004; Mujumdar and Passos, 2000). Therefore, alternative methods of drying or dehydration of products before drying are sought to minimize energy consumption and to improve the final product quality (Min et al., 2010).

Osmotic dehydration (OD) is a non-thermal process which utilises osmosis occurring after immersion of plant tissue in hypertonic aqueous solution. The difference between water activity and osmotic pressure in plant tissue and ambient hypertonic solution generates two oppositely directed fluxes. While water permeates through the cell membrane from plant tissue to solution, soluble solids from the solution penetrate the cell membrane (Pan et al., 2003). In this way even $50 \%$ of water initially present in the material can be removed at a relatively low expenditure of energy. The literature contains earlier findings that state (Lewicki and Lenart, 2006) a convective drying needs about $5 \mathrm{MJ}$ per kilogram of evaporated water, compared to 0.1-2.4 MJ per kilogram of water removed in osmotic dehydration.

Both in previous papers published by the authors of the present study (Kowalski et al., 2009) and in other publications (Konopacka et al., 2009; Maftoonazad, 2010) it was proved that quality of dried products initially dehydrated with osmotic solution is much better that those without OD pre-treatment. Additionally, OD contributes to reducing final energy consumption of the whole process, by shortening the drying time and lowering the process temperature. Products pretreated using OD require further processing to attain desirable moisture content that would guarantee their stable state. Therefore, OD is very often used as a pre-treatment process preceding the main drying operation (air, vacuum, microwave, etc.).

Despite numerous studies of this subject, the knowledge of parameters which possibly best stimulate OD process is still scarce. The aim of the studies presented in this paper was to investigate the influence of osmotic agent type and its aqueous concentration on the kinetics of OD and on the final product quality. In comparison to the authors of the previous paper (Kowalski et al., 2009) this study focuses on three types of osmotic agents (sucrose, fructose, glucose) and three solution concentrations $(20,40$ and $60 \%)$. The product quality was assessed not only on the basis of visual appearance but also using precise colorimetric measurements. It was found that such a combined process improves significantly the final product quality.

\section{MATERIALS AND METHODS}

\subsection{Sample preparation}

Fresh carrots (Daucus carota L.) from the local market were used as the experimental material. Each carrot was washed, cleaned and peeled. Next, rectangular samples $40 \times 30 \times 5 \mathrm{~mm}$ in size having approximately similar weight $(8 \mathrm{~g})$ were prepared with a ceramic knife.

\subsection{Dehydration process}

Osmotic dewatering processes using aqueous solutions of sucrose (SUC), fructose (FRU) and glucose (GLU) in three concentrations of 20,40 and 60\% were examined. The solutions were prepared in a room temperature $\left(21^{\circ} \mathrm{C}\right.$ ) by mixing (for $10 \mathrm{~min}$ ) the predetermined amount of osmotic agent with 
distilled water. The ratio of solution to sample mass was 25:1 to avoid dilution effect. A given volume $(200 \mathrm{~mL})$ of the solution was poured into a transparent container (capacity $750 \mathrm{~mL}$ ). Next, the sample was immersed in the solution and the container was closed with a hubcap to prevent water evaporation. Dewatering lasted 6 hours. Changes of the sample mass were measured after 1.5, 3 and 6 hours of the osmotic process using the balance model AJH-2200CE produced by VIBRA (accuracy of $0.01 \mathrm{~g}$ ). For measurement purposes the sample was taken out from the solution and dried delicately with an absorbent paper. After finishing the OD each sample was convectively dried up in the laboratory hybrid dryer (see Kowalski et al., 2009).

\subsection{Convective drying process}

The osmotically dewatered sample was placed in the hybrid dryer chamber. All the tests of convective drying were carried out with the following setting of drying parameters:

- velocity of the air $v=1.2 \mathrm{~m} / \mathrm{s}$

- temperature of the air $T=55^{\circ} \mathrm{C}$

Air relative humidity $(R H)$ was not set manually or controlled during drying, but it was measured in each drying test $(R H=21 \%$ on average). The sample mass loss was measured using the balance WPS $2100 / \mathrm{C} / 1$ produced by Radwag (Poland) with precision of $0.01 \mathrm{~g}$. The temperature of the sample surface was measured by the pyrometer model MI produced by Raytek (USA) with precision of $1^{\circ} \mathrm{C}$. Air velocity was measured with anemometer at the intake to the drying chamber. All the mentioned parameters (sample mass, temperature, etc.) were recorded during the whole process and stored in a standard personal computer equipped with the data acquisition software.

\subsection{Quality assessment of products}

Each sample was photographed (before OD, after OD, and after final convective drying) for visual assessment of its quality. The colour of the sample surface was measured before and after OD as well as after drying with the Konica Minolta CR400 colorimeter (illuminant D65, observer $2^{\circ}$ ) and expressed in CIELab colour space (precision 0.01). Before each test the colorimeter was calibrated on a special white plate. Each test was carried out on a white ceramic plate to provide identical measurement conditions and eliminate background influence. Two spots for colour measurement were randomly chosen on each sample and in each spot ten measurements of colour parameters $\left(L^{*}, a^{*}, b^{*}\right)$ were conducted. Next, the arithmetic mean was calculated. On the basis of the obtained results the differences in samples' colour (before and after drying) were assigned as a relative colour change parameter $\Delta E$ according to equation:

$$
\Delta E=\sqrt{\Delta L^{*}+\Delta a^{2}+\Delta b *^{2}}
$$

Additionally, another relative colour change parameter $\triangle E 00$ was evaluated in Konica Minolta Color Data Software - SpectraMagic NX-CMs-100W (ver. 1.9). This parameter is much more comprehensive and takes into account imperfections of the human eye in colour perception and other factors which affect color measurements.

\subsection{Determination of process parameters}

Initial moisture content $\left(M C_{i}\right)$ of the material was determined with the moisture analyzer model XM120 (precision $0.01 \%$ ), produced by Precisa (Switzerland). Moisture content in current time $\left(M C_{t}\right)$ is expressed as the ratio of moisture mass $\left(m_{M}\right)$ to the initial mass of wet sample $\left(m_{i}\right)$ according to Equation (2): 


$$
M C_{t}=\frac{m_{M}}{m_{i}}=\frac{m_{t}-s_{t}}{m_{i}}
$$

where $m_{t}$ is the actual sample mass and $s_{t}$ is the mass of dry body at time $t$.

Solid Gain $(S G)$ and water loss $(W L)$ were evaluated in compliance with Equations (3) and (4):

$$
\begin{gathered}
S G=\frac{s_{t}-s_{i}}{m_{i}} \\
W L=\frac{\left(m_{i}-m_{t}\right)+\left(s_{t}-s_{i}\right)}{m_{i}}
\end{gathered}
$$

where $s_{i}$ is initial mass of dry body (of fresh - not processed sample).

The mass of the dry bodies $\left(s_{t}\right.$ and $\left.s_{i}\right)$ was determined after 24 -hrs drying at $T=75^{\circ} \mathrm{C}$ in convective dryer, model SML42/250/M, produced by Zalmed (Poland).

\section{RESULTS AND DISCUSSION}

\subsection{Kinetics of osmotic dehydration}

Figure 1 presents the plot of moisture content $(M C)$ versus time $(t)$ for 3 different osmotic agents in three different concentrations.

It can be easily noticed that the concentration of hypertonic solution has a decisive influence on the kinetics of osmotic dehydration (OD). In each case the volume of removed water and the rate of the process depend on the concentration of the solution. Obviously, the final moisture content $\left(M C_{f}\right)$ diminished with an increase of osmotic solution concentration. Moreover, the shape of the curves proves that the time of OD in some cases was not sufficient to reach the equilibrium state between the solution and the dehydrated body. Curves for $40 \%$ (except fructose) and for $60 \%$ solutions have a distinctly falling tendency, while those for all $20 \%$ (and for $40 \%$ fructose) solutions attained stable equilibrium level after $360 \mathrm{~min}$ dehydration. The most important OD parameters are presented in Table 1.

Table 1. Parameters of osmotic dehydration for carrot

\begin{tabular}{|c|c|c|c|c|c|}
\hline $\begin{array}{c}\text { Osmotic } \\
\text { Agent }\end{array}$ & $\mathrm{Cp}[\%]$ & $M C_{i}\left[\mathrm{~kg} / \mathrm{kg}_{(\mathrm{wb})}\right]$ & $S G\left[\mathrm{~kg} / \mathrm{kg}_{(\mathrm{wb})}\right]$ & $W L[\mathrm{~kg} / \mathrm{kg}(\mathrm{wb})]$ & $O D R_{\max }[\mathrm{g} / \mathrm{min}]$ \\
\hline \multirow{4}{*}{ Glucose } & 20 & $0.88 \pm 2.08 \times 10^{-3}$ & $0.03 \pm 2.92 \times 10^{-3}$ & $0.16 \pm 3.98 \times 10^{-3}$ & $7.39 \times 10^{-3}$ \\
\cline { 2 - 6 } & 40 & $0.87 \pm 2.01 \times 10^{-3}$ & $0.08 \pm 2.82 \times 10^{-3}$ & $0.32 \pm 3.70 \times 10^{-3}$ & $1.49 \times 10^{-2}$ \\
\cline { 2 - 6 } & 60 & $0.89 \pm 1.98 \times 10^{-3}$ & $0.11 \pm 2.80 \times 10^{-3}$ & $0.58 \pm 3.51 \times 10^{-3}$ & $2.38 \times 10^{-2}$ \\
\hline \multirow{4}{*}{ Fructose } & 20 & $0.89 \pm 2.00 \times 10^{-3}$ & $0.04 \pm 2.81 \times 10^{-3}$ & $0.17 \pm 3.82 \times 10^{-3}$ & $8.06 \times 10^{-3}$ \\
\cline { 2 - 6 } & 40 & $0.88 \pm 1.98 \times 10^{-3}$ & $0.09 \pm 2.78 \times 10^{-3}$ & $0.29 \pm 3.68 \times 10^{-3}$ & $1.22 \times 10^{-2}$ \\
\cline { 2 - 6 } & 60 & $0.92 \pm 1.95 \times 10^{-3}$ & $0.17 \pm 2.77 \times 10^{-3}$ & $0.56 \pm 3.48 \times 10^{-3}$ & $1.96 \times 10^{-2}$ \\
\hline \multirow{5}{*}{ Sucrose } & 20 & $0.88 \pm 1.89 \times 10^{-3}$ & $0.02 \pm 2.65 \times 10^{-3}$ & $0.1 \pm 3.65 \times 10^{-3}$ & $4.33 \times 10^{-3}$ \\
\cline { 2 - 6 } & 40 & $0.88 \pm 2.01 \times 10^{-3}$ & $0.13 \pm 2.84 \times 10^{-3}$ & $0.34 \pm 3.70 \times 10^{-3}$ & $8.94 \times 10^{-3}$ \\
\cline { 2 - 6 } & 60 & $0.89 \pm 1.97 \times 10^{-3}$ & $0.14 \pm 2.79 \times 10^{-3}$ & $0.48 \pm 3.55 \times 10^{-3}$ & $1.77 \times 10^{-2}$ \\
\hline
\end{tabular}



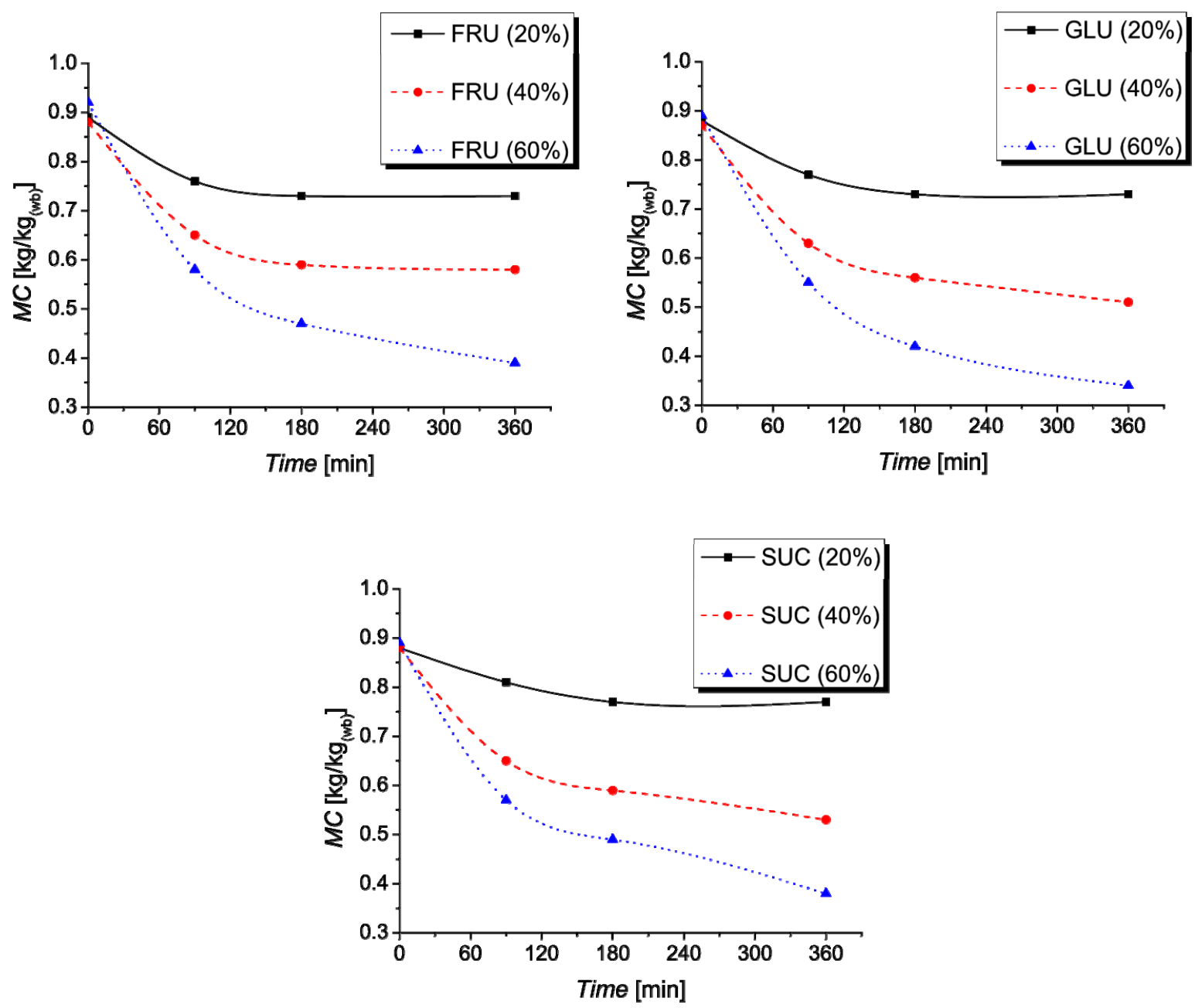

Fig. 1. Moisture content versus time for carrot during osmotic dehydration

The analysis of the data given in Table 1 allows to state that the type of osmotic agent used in this study does not have a significant influence on dewatering effect of carrot. Every assigned parameter such as $M C_{f}$, water loss $(W L)$ and solid gain $(S G)$ differentiate insignificantly, that is, not more than $0.05 \mathrm{~g} / \mathrm{g}_{(\mathrm{wb})}$ for a given type and the concentration of solution. However, the concentration has a decisive influence on each of the above mentioned parameters. The higher concentration is used, the bigger amount of water is removed from carrot, but also more solute solid penetrate the carrot cells. $S G$ varied between $0.02 \pm 2.65 \times 10^{-3} \mathrm{~g} / \mathrm{g}_{(\mathrm{wb})}(\mathrm{SUC})$ and $0.04 \pm 2.81 \times 10^{-3} \mathrm{~g} / \mathrm{g}_{(\mathrm{wb})}$ (FRU) for $20 \%$ solutions, while for $60 \%$ solutions $S G$ achieved the level of $0.11 \pm 2.80 \times 10^{-3} \mathrm{~g} / \mathrm{g}_{(\mathrm{wb})}(\mathrm{GLU})$ and $0.17 \pm 2.77 \times 10^{-3} \mathrm{~g} / \mathrm{g}_{\text {(wb) }}$ (FRU). Changes of $W L$ were more distinct as for $20 \%$ solutions $W L$ was on average $0.15 \mathrm{~g} / \mathrm{g}_{\text {(wb) }}$ but for more concentrated solutions it rose as high as to $0.58 \mathrm{~g} / \mathrm{g}_{(\mathrm{wb})}(\mathrm{GLU})$.

The maximum rate of osmotic dehydration $\left(O D R_{\max }\right)$, measured at 90 -th minute of the dewatering process, depended both on the solution concentration and on the type of osmotic agent. The highest $O D R_{\max }$ value was obtained for $60 \%$ solution of glucose $\left(2.38 \times 10^{-2} \mathrm{~g} / \mathrm{min}\right)$ whereas the lowest one for $20 \%$ sucrose solution $\left(4.33 \times 10^{-3} \mathrm{~g} / \mathrm{min}\right)$. It was also observed that dewatering of carrot with sucrose solutions is evidently slower than by applying either fructose or glucose solutions.

\subsection{Kinetics of air drying}

Figure 2 presents the drying curves of the fresh and the osmotically dehydrated samples. The convective drying $(\mathrm{CV})$ of fresh (not dehydrated) samples was carried out to visualize the influence of OD pre-treatment on the drying time of carrot. Theoretically, the samples with initial osmotic 
dewatering should be dried faster because of smaller moisture content than that found in fresh material. Nonetheless, shorter drying time compared to CV drying of fresh sample was observed only for samples dewatered with fructose and glucose solutions. For samples with OD in sucrose solutions, the time of CV drying was very similar or even longer in comparison to that of not processed samples ( 340 and 350-360 min respectively). The final moisture content $M C_{f}$ of samples processed with OD was on average: $0.08 \pm 1.89 \times 10^{-3} \mathrm{~g} / \mathrm{g}_{\text {(wb) }}(\mathrm{GLU}), 0.04 \pm 2.01 \times 10^{-3} \mathrm{~g} / \mathrm{g}_{(\mathrm{wb})}(\mathrm{FRU})$ and $0.07 \pm 1.98 \times 10^{-3} \mathrm{~g} / \mathrm{g}_{(\mathrm{wb})}$ (SUC). The $M C_{f}$ of fresh (not OD) samples after CV drying was on average $0.02 \pm 1.92 \times 10^{-3} \mathrm{~g} / \mathrm{g}_{(\mathrm{wb})}$. Differences between particular results result from the income of solute solid and crystallization of substances on the sample surface. The sugar settled on the sample surface blocked up moisture outflow and thus limited the superficial film of water that is normally created on the surface during the constant drying rate period. This is possibly the main reason for the insignificant shortening of the drying time and the increase of $M C_{f}$ with respect to that in pure convective drying.
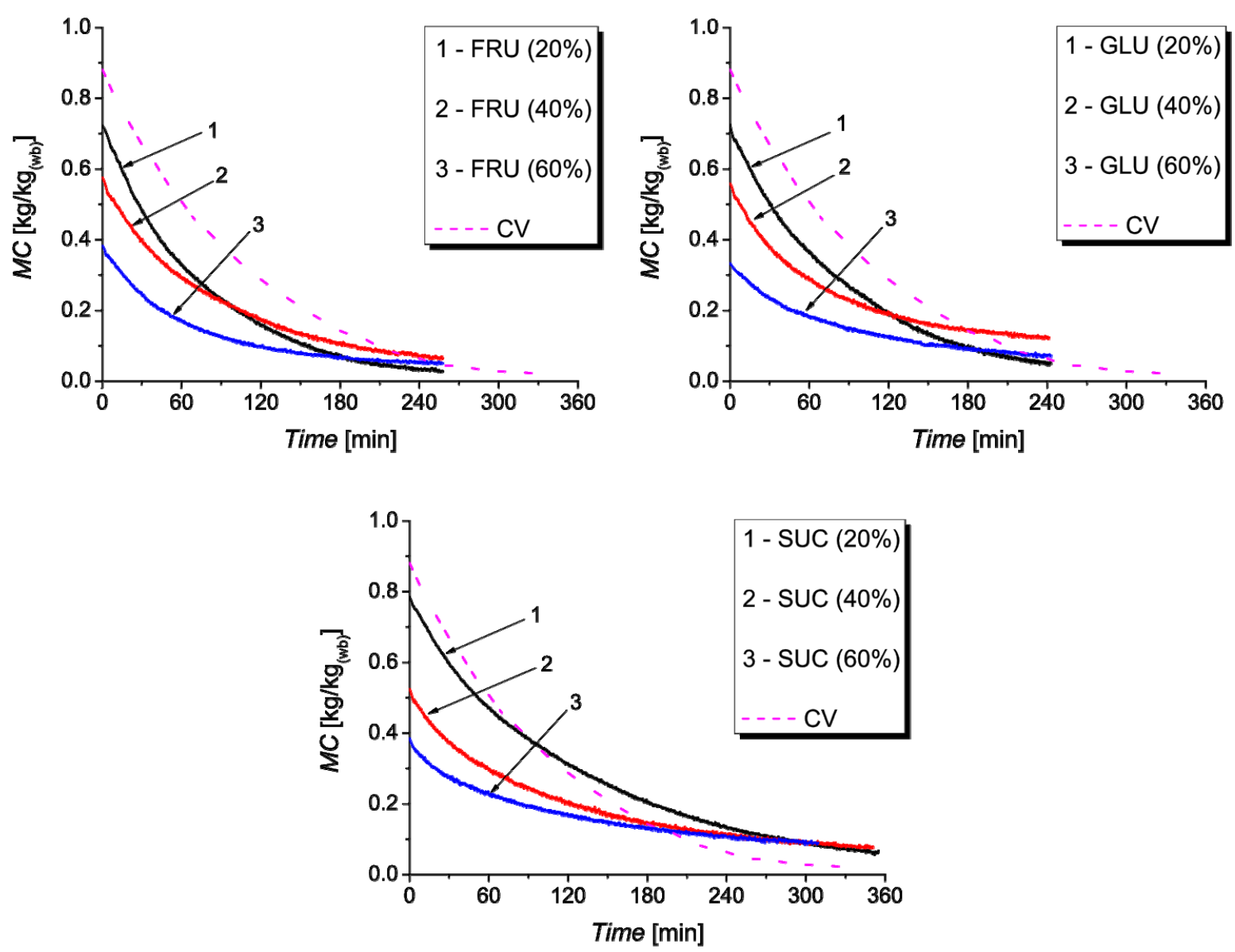

Fig. 2. Convective drying curves for carrot samples with and without osmotic pretreatment

\subsection{Quality of sample}

Figure 3 presents photos of the samples dehydrated in sucrose solutions. As can be seen dehydration causes shape deformation and shrinkage. A range of such changes depend on the concentration and kind of solution. The samples dehydrated with $20 \%$ sucrose solution look similarly to the fresh samples. The deformation and shrinkage are insignificant, the colour and texture of the samples changed to a lesser degree. Conversely, the samples dehydrated with $60 \%$ solution of sucrose look absolutely differently. The samples are deformed and shrunk significantly, the colour and texture of the samples differ distinctly with respect to the fresh samples. The photos of the samples dehydrated in 
sucrose solution were selected because the differences in appearance were in this case most distinguishable. The samples dehydrated in fructose or glucose solution were not deformed and shrunk to a such visible degree.

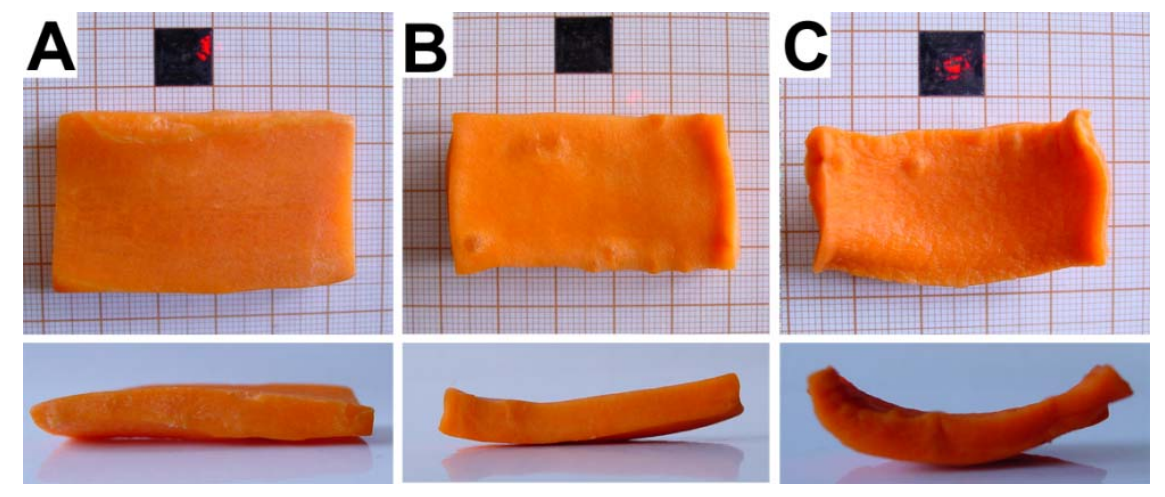

Fig. 3. Photos of samples dewatered with sucrose solutions: A) $20 \%$, B) $40 \%$ C) $60 \%$

The photos of fresh and dehydrated samples after convective drying are presented in Figure 4.
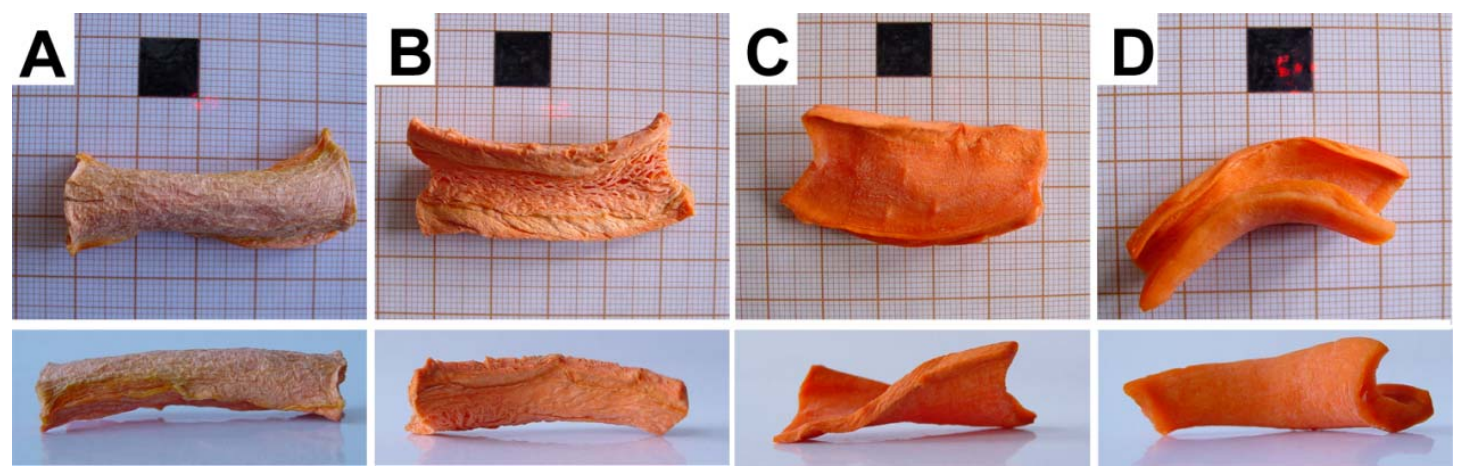

Fig. 4. Photos of samples after convective drying: A) fresh, B) FRU 20\%, C) GLU $40 \%$, D) SUC $60 \%$

As expected the quality of the fresh carrot dried convectively is very poor. The samples are deformed, their surfaces became hard, rough and shrunk, and lost the initial colour. To sum up, the quality of the products obtained in this process is far from desirable and it exceeds the product's commercial value. The samples initially dehydrated with the hypertonic solutions look better. Although the shape of these samples does not differentiate significantly from the others, the colour and texture are much better in comparison to those without OD pretreatment.

The relative colour parameters $(\Delta E, \Delta E 00)$ are presented for each of the studies processes in Table 2 . These parameters indicate differences between colours for fresh (not processed) and processed samples.

The results obtained for convectively dried samples confirmed the previous observation that a long drying in a relatively high temperature causes a meaningful colour change as a consequence of biochemical (enzymatic and non-enzymatic) reactions (e.g. Millard polycondensation). The application of OD pretreatment resulted in improved colour preservation and the differences between colours of the fresh and dried samples were considerably smaller.

The influence of the solution concentration on the sample colour was noticed only in the case of glucose solutions. The more concentrated solution was applied the smaller colour change was obtained. 
For the two other osmotic agents (fructose and sucrose) differences between several concentrations were imperceptible or difficult to observe. As the influence of osmotic agent is concerned, it can be stated that the best colour was observed in samples dewatered in glucose solutions, and the worse colours in those pretreated with sucrose solution.

Table 2. Colorimetric data after convective drying of fresh and osmotically processed carrot samples

\begin{tabular}{|c|c|c|c|}
\hline $\begin{array}{c}\text { Osmotic } \\
\text { Agent }\end{array}$ & $\mathrm{Cp}[\%]$ & $\Delta E[-]$ & $\Delta E 00[-]$ \\
\hline \multirow{3}{*}{ Glucose } & 20 & $11.84 \pm 0.09$ & $9.87 \pm 0.01$ \\
\hline & 40 & $6.76 \pm 0.14$ & $4.03 \pm 0.01$ \\
\hline & 60 & $3.26 \pm 0.39$ & $2.58 \pm 0.01$ \\
\hline \multirow{3}{*}{ Fructose } & 20 & $10.19 \pm 0.2$ & $5.76 \pm 0.01$ \\
\hline & 40 & $10.34 \pm 0.37$ & $5.43 \pm 0.01$ \\
\hline & 60 & $11.27 \pm 0.35$ & $4.09 \pm 0.01$ \\
\hline \multirow{3}{*}{ Sucrose } & 20 & $12.84 \pm 1.65$ & $9.90 \pm 0.01$ \\
\hline & 40 & $11.00 \pm 0.13$ & $7.19 \pm 0.01$ \\
\hline & 60 & $12.95 \pm 0.24$ & $8.30 \pm 0.01$ \\
\hline \multicolumn{2}{|c|}{$\mathrm{CV}$} & $17.01 \pm 0.13$ & $11.52 \pm 0.01$ \\
\hline
\end{tabular}

\section{CONCLUSIONS}

The following conclusions can be drawn on the basis of the results presented in this paper:

- The solution concentration has a decisive influence on the effectiveness of osmotic dewatering. The higher concentration the bigger amount of water is removed from material ( $W L$-increased, $M C_{f}$ decreased), but more solute agent penetrated carrots cells ( $S G$-increased).

- The parameters $W L, S G, \mathrm{MC}_{\mathrm{f}}$ differentiate only slightly (about $0.5 \mathrm{~g} / \mathrm{g}_{(\mathrm{wb})}$ ) for various osmotic agents, so the type of agents does not have a significant influence on osmotic dewatering, but does have an influence on $O D R_{\max }$. The highest $O D R_{\max }$ which amounted to $2.38 \times 10^{-2} \mathrm{~g} / \mathrm{min}$ was achieved for $60 \%$ solution of glucose, and the lowest one of $4.33 \times 10^{-3} \mathrm{~g} / \mathrm{min}$ for $20 \%$ sucrose solution.

- Preliminary osmotic dewatering did not shorten remarkably the time of the final convective drying. Although this time for fructose and glucose was a bit shorter in comparison to the samples dried without osmotic pretreatment, it was similar or even longer for sucrose.

- The samples pretreated with higher concentrated solutions evidenced in some cases a higher final MCf than those without osmotic pretreatment. This phenomenon results probably from the fact that carrot pores were penetrated by the solute solid and from the fact that crystallization on the sample surface which could have blocked the moisture outflow.

- Osmotic dewatering influences the sample appearance as far as it concerns its shape and colour. The sample deformation and shrinkage depend on the solution concentration. The smallest changes occurred for $20 \%$ solution and the biggest ones for $60 \%$.

- On the basis of the colorimetric analysis and photo visualization it can be stated that osmotic dewatering better preserved colour, structural and textural properties of carrot samples, whereas shape deformations and shrinkage were very similar in both osmotically pretreated and not pretreated samples. 
This work was carried out as a part of research project No. N N209 373639 sponsored by the Ministry of Science and Higher Education of Poland.

\section{SYMBOLS}

$\begin{array}{ll}a^{*} & \text { CIELab colour space parameter, - } \\ b^{*} & \text { CIELab colour space parameter, - } \\ C p & \text { concentration, } \% \\ L^{*} & \text { lightness of colour in CIE colour space, - } \\ m & \text { mass, } \mathrm{g} \\ M C & \text { moisture content (wet basis), } \mathrm{g} / \mathrm{g} \\ O D R & \text { osmotic drying rate, } \mathrm{g} / \mathrm{min} \\ R H & \text { air relative humidity, } \% \\ S & \text { mass of dry body, } \mathrm{g} \\ S G & \text { solid gain, } \mathrm{g} / \mathrm{g} \\ T & \text { temperature, }{ }^{\circ} \mathrm{C} \\ t & \text { time, min } \\ v & \text { velocity of the air, } \mathrm{m} / \mathrm{s} \\ W L & \text { water loss, } \mathrm{g} / \mathrm{g} \\ \Delta E & \text { relative colour change parameter, - } \\ & \\ \text { Subscripts } & \\ f & \text { final } \\ i & \text { initial } \\ M & \text { moisture } \\ \text { max } & \text { maximum } \\ t & \text { at time } t \\ w b & \text { wet basis }\end{array}$

\section{REFERENCES}

Chua K.J., Mujumdar A.S., Hawlader M.N.A, Chou S.K., Ho J.C., 2001. Convective drying of agricultural products. Effect of continuous and stepwise change in drying air temperature. Dry. Technol., 19, 1949-1960. DOI: $10.1081 /$ DRT-100107282

Konopacka D., Jesionkowska K., Klewicki R., Bonazzi C., 2009. The effect of different osmotic agents on the sensory perception of osmo-treated dried fruit. J. Hortic. Sci. Biotechnol. ISAFRUIT Special Issue, 80-84.

Kowalski S.J., Mierzwa D., Śronek B., 2009. Drying of osmotically dehydrated biological materials. Chem. Proc. Eng., 30, 559-568.

Krokida M.K., Tsami E., Maroulis Z.B., 1998. Kinetics on color changes during drying of some fruits and vegetables. Dry. Technol., 16, 667-685. DOI: 10.1080/07373939808917429

Kudra T., 2004. Energy aspects in drying. Dry. Technol., 22, 917-932. DOI: 10.1081/DRT-120038572

Lewicki P.P., Lenart A., 2006. Osmotic dehydration of fruits and vegetables, In: Mujumdar A.S. (Ed.), Handbook of industrial drying, 3-rd edition, Taylor \& Francis Group, LLC, 665-688.

Maftoonazad N., 2010. Use of osmotic dehydration to improve fruits and vegetables quality during processing. Recent Pat. on Food, Nutr. Agric., 2, 233-242. DOI: 10.2174/1876142911002030233

Markowski M., Stankiewicz I., Zapotoczny P., Borowska J., 2006. Effect of variety on drying characteristics and selected quality attributes of dried carrots. Dry. Technol., 24, 1011-1018. DOI: 10.1080/07373930600776191 
Min Z., Hao J., Rui-Xin L., 2010. Recent developments in microwave-assisted drying of vegetables, fruits, and aquatic products - drying kinetics and quality considerations. Dry. Technol., 28, 1307-1316. DOI: $10.1080 / 07373937.2010 .524591$

Mujumdar A.S., Law C.L., 2010. Drying technology: Trends and applications in postharvest processing. Food Bioproc. Technol., 3, 843-852. DOI 10.1007/s11947-010-0353-1

Mujumdar A.S., Passos M.L., 2000. Innovation in drying technologies, In: Mujumdar A.S. (Ed.), Drying technology in agriculture and food sciences. Science Publishers Inc., Enfield, New Hampshire.

Pan Y.K., Zhao L.J., Zhang Y., Chen G., Mujumdar A.S., 2003. Osmotic dehydration pretreatment in drying of fruits and vegetables. Dry. Technol., 21, 1101-1114. DOI: 10.1081/DRT-120021877

Sagar V.R., Suresh Kumar P., 2010. Recent advances in drying and dehydration of fruits and vegetables: A review. J. Food Sci. Technol. 47, 15-26. DOI: 10.1007/s13197-010-0010-8

Santos P.H.S., Silva M.A., 2008. Retention of vitamin c in drying processes of fruits and vegetables-A review. Dry. Technol., 26, 1421-1437. DOI: 10.1080/07373930802458911

Vázquez-Vila M. J., Chenlo-Romero F., Moreira-Martínez R., Pacios-Penelas B., 2009. Dehydration kinetics of carrots (Daucus carota L.) in osmotic and air convective drying processes. Span. J. Agric. Res., 7, 869-875. 